\title{
Research on Travel Behavior with Car Sharing under Smart City Conditions
}

\author{
Zhimin Tao, ${ }^{1}$ Quan Nie $\mathbb{D}^{2}{ }^{2}$ and Weibin Zhang $\mathbb{D i}^{2}$ \\ ${ }^{1}$ School of Transportation Science and Engineering, Beihang University, Beijing 100191, China \\ ${ }^{2}$ School of Electronic and Optical Engineering, Nanjing University of Science and Technology, Nanjing 210094, China
}

Correspondence should be addressed to Weibin Zhang; weibin.zhang@njust.edu.cn

Received 26 May 2020; Revised 27 July 2020; Accepted 28 January 2021; Published 28 February 2021

Academic Editor: Yuan Gao

Copyright (c) 2021 Zhimin Tao et al. This is an open access article distributed under the Creative Commons Attribution License, which permits unrestricted use, distribution, and reproduction in any medium, provided the original work is properly cited.

As a sustainable transportation system, car-sharing schemes have been attracting increasing attention. A large amount of research and practice has proved that the application and promotion of car sharing can help reduce the number of private cars purchased, increase the utilization rate of automobiles, effectively alleviate traffic congestion, save energy, and reduce emissions. Therefore, research on car sharing is imperative. The logit model is widely used in studies on car sharing and is an effective tool for analyzing traffic problems. This study first introduces the status of research into car sharing and analyzes the potential users and market prospects for shared cars. The study then provides the results from a questionnaire survey in Nanjing, China, to obtain sample data. Finally, a mixed logit model is established to analyze the influencing factors of car-sharing selection behavior. The results show that factors such as an individual's housing situation and income significantly affect car-sharing decisions and that respondents who choose to use shared cars are relatively similar to commuters. The main contribution of this study is to use empirical analysis to determine the key influencing factors of car-sharing behavior in China and to provide practical insights for commercial practitioners and traffic planners.

\section{Introduction}

In the past decade, the rapid development of urban modernization has brought many social problems to China's transportation systems. Since 2010, China has become one of the largest car manufacturing regions in the world, producing tens of millions of cars [1]. The increase in private cars has had a huge negative impact on China's urban development and caused environmental issues, such as traffic congestion, air pollution, and overloaded parking areas, which have meant that policy makers must find effective solutions to control the level of car ownership. Car sharing is considered a possible innovative approach to solving these problems and is growing rapidly.

In recent years, as a new and more sustainable mode of transportation, car sharing in many countries is causing a shift in car ownership from private transportation to shared services. The first car-sharing organization can be traced back to Zurich, Switzerland, in 1948. However, for economic reasons, the development of car-sharing systems was not smooth in the years that followed. It was not until the 1980s that car sharing first entered the market, and in the early 1990s, there was an increase in car sharing due to the popularity of ICT and mobile services [2]. In recent years, with the development of electric vehicles, it has become possible to use these in car sharing. Electric vehicle sharing avoids the high cost and range issues of these vehicles and has great potential in reducing operating costs and greenhouse gas emissions [3].

Car sharing can improve vehicle utilization, reduce air pollution, and relieve urban traffic pressure while also raising awareness among citizens of private car use and environmental protection. From the perspective of building sustainable cities, vehicles used for car sharing are usually new energy vehicles such as electric car, and they play a vital role in reducing urban emissions and congestion [4]. Some researchers have found that analyzing the characteristics of user behavior is very important for the development of car- 
sharing services because behavior can fundamentally explain some system operating problems. Research in Europe and the United States has analyzed the behavior patterns of users and concluded that behavior is a key factor in determining the successful operation of car-sharing services $[2,5]$.

Based on data from shared-car travel questionnaires, this study establishes a mixed logit model to analyze the significant influencing factors for residents in Nanjing, China, in choosing shared-car travel. This study explores the pattern rules of residents' choice behavior in car sharing and quantifies the interactions and influence mechanisms of various factor. Finally, based on the research results, practical suggestions are made for policy makers and commercial practitioners seeking to promote the development of car sharing in China as a means of alleviating the problems of urban transportation and environmental impacts. The main contribution of this study is to conduct empirical analysis of the key influencing factors of China's car-sharing choice behavior and to propose effective options that will help with the implementation and development of car sharing in China.

The second chapter of this study reviews the literature, outlines the current status of car sharing and the potential user market, and conducts a comprehensive assessment of the modeling methods used in previous research. The third chapter presents the research methods adopted in this study, including data acquisition methods, modeling analysis methods, and their parameter tests. The fourth chapter describes the questionnaire design, summarizes the questionnaire data, and predicts the model simulation results based on the intuitive results from the sample data. Next, the fifth chapter evaluates the simulation results, focusing on the empirical results and discussing the significant influencing factors for residents in Nanjing, China, to choose carsharing travel. Finally, we summarize our findings and propose a future research direction.

\section{Literature Review}

2.1. Research Status. A number of studies in Europe and the United States have analyzed car-sharing users' behavior patterns. Some studies have shown that, after joining a carsharing club, members used shared cars less than three times per month, and this was mainly for shopping, visiting friends, leisure, and vacations. A small proportion of members used shared cars for regular commuting, and most members used them to carry heavy items or to travel to many destinations [6]. The development of China's car-sharing system is still in the initial exploratory stage. Due to a lack of government and social support, there is relatively little research on car sharing in China.

Current research has illustrated the potential benefits of car-sharing systems, including benefits to society and users. A study by Nijland and Meerkerk [7] showed that car sharing can effectively reduce car ownership and can remove the need for a second or third car. Car sharing has been identified as a new model that can reduce costs, improve transportation efficiency, reduce car ownership, reduce traffic congestion, reduce parking demand, and improve the environment [8]. In terms of the users' choice of car-sharing behavior, previous studies indicate that individuals' personal situations have a stronger influence on their willingness to use shared cars than the properties of the cars [9]. Other studies have shown that the service cost gap and service characteristics play a vital role in the choice of car sharing [10-12]. These factors should be taken into account when developing car sharing in emerging markets such as China.

Car sharing was introduced into mainland China in 2015, and many auto companies have since started to operate shared cars in large cities. Currently, the main shared car service companies in Nanjing are EvCard, GoFun, and GreenGo. Most of these companies use new energy vehicles as shared vehicles. Several studies have shown that China is a potential development and application market and have proposed some potential market segmentation systems [13]. Although some studies on the behavioral patterns of sharedcar users provide valuable information, most studies only analyze the users' intentions. Recently, many researchers have concluded that analyzing the potential demand of users' travel behavior is important in determining the successful operation of a car-sharing system [4].

2.2. Potential Market and Users. The potential market for shared cars has been analyzed in a number of previous studies, and these have found that the main groups using shared cars are community residents, business circles, college students, low-income groups, and commuters [14]. Studies have shown the market potential of car sharing in university campuses, finding that the university market has the ability to develop and expand the scope of a community or commercial market [12]. Younger people prefer car sharing because their attitudes toward cars are different from older generations; they consider that car sharing is a new form of car culture [15]. Shared cars are more convenient in urban centers than in suburbs because of the higher population densities; therefore, people in downtown areas are more likely to use car sharing. In addition, the frequency of car use is an active driving force for car sharing, and highfrequency users are more likely to join shared car services to meet their transportation needs [16]. Kim et al. [17] found that the availability of shared cars plays a crucial role in choice behavior, based on a hybrid selection model. Research by Gheorghiu and Delhomme [18] analyzed the use of carpooling for different types of daily travel and found that the commonest use was leisure travel, followed by shopping, then work, and children-related travel. This provides a reference for the market analysis of shared car services.

Wang et al. [13] considered that the potential for car sharing in the Chinese market is very large and that sharedcar sites located near public transport facilities will attract more potential users. This study also pointed out that groups with the most potential to join car-sharing systems were the most educated citizens, young people, and middle-income people [16]. Many researchers believe that people who are familiar with the concepts of car sharing are more likely to join a system. Shaheen [14] conducted a survey of 840 respondents in Beijing to explore the impact of familiarity on 
participation in car-sharing systems and found a correlation between the degree of familiarity of respondents and their choice of interests. This means that the deepening of familiarity will increase the likelihood of participation.

\subsection{The Main Modeling Method. The discrete choice model} is an effective tool for the study of shared-car travel behavior. A major current research direction is the study of the characteristics of shared-car users' travel behavior. In some studies, population characteristics were modeled using carsharing user samples and analyzed using logit models. To understand the driving factors in the choice of urban carsharing systems, Luca and Pace [11] studied multiple logit, hierarchical logit, cross-nested logit, and mixed logit models and determined which was most effective. The logit model is a type of the discrete selection model with various forms, such as binomial log [19], multiple logit [20], hierarchical logit, cross logit, nested logit, and hybrid logit [21], which are widely used to model travel decisions for car-sharing users.

The mixed logit model provides insights into travel behavior, decision-making, and demand forecasting and provides a wealth of theoretical support. In particular, it contributes greatly to travel demand theory, which helps transport policy analysis [22]. The characteristics of heterogeneity, the less restrictive substitution patterns, and the correlation between unobserved variables mean that the mixed logit model has a good effect in analyzing traffic behavior. Furthermore, because it enhances the behavioral connection between individual travel demand and the attributes of the transportation system, the mixed logit model can better analyze the factors that influence the behavior of car-sharing choices.

\section{Research Methods}

3.1. Research Design. As a megacity, Nanjing has undergone rapid economic growth, motorization, and urbanization in the past few decades. The focus of this study is to use logit models to analyze the factors that affect the choice of shared-car modes, to explore the patterns of residents' choices of shared-car behavior, and to quantify the interaction and influence mechanism of each factor. This study uses quantitative analysis methods including the design of stated preference- (SP-) based survey questionnaires, the collection of questionnaire data, and the establishment of a logit model to simulate data analysis.

There are three main approaches to this study. First, in order to better understand the concept of car-sharing systems, a large number of previous studies on car sharing in China and other countries are reviewed. Based on this previous research, we introduce the modeling method of this study and the main data to be collected. Second, we identify important data collection samples and design a questionnaire to enable analysis of the factors influencing Nanjing citizens' choice of car sharing, based on the SP method, and we check the validity and reliability of the important variables of the data. Finally, sample data from logit model analysis are used to estimate multiple unknown parameters, and the research objectives of this study are quantified and explained according to simulation results.

3.2. Data Collection Method. This section illustrates the advantages and disadvantages of the SP survey method used in the questionnaire design. The SP survey method can analyze the behavior of the respondents under various hypothetical scenarios, reflecting the impact of unobserved variables such as comfort, convenience, and safety on the respondents. It is also possible to test the basic attributes of a research area that does not exist in real life.

In recent years, the SP survey [23] has been widely used in research topics such as travel destination selection, transportation mode selection, and travel time value analysis. The advantages of questionnaire data based on the SP method are that

(1) The data have extremely high operability

(2) The data error can be adjusted

(3) The set of selection options is determined for the stated preference survey

However, the SP survey is not perfect. It can easily lead to various biases, such as survey bias in which the respondents tend to reinforce their first choice based on other incentives. Content effect bias occurs when respondents respond to questions based on situations they have not experienced before, and when interviewees receive too much information from the investigator, they are bound by circumstances that make them confused about the decision. Nevertheless, these biases can be mitigated through proper design and management [20].

China is an emerging car-sharing market, and the concept of innovative car sharing is not common in Nanjing. The preference survey asks interviewees to respond to things that exist in reality, and it relies on the actual choices of the respondents. Therefore, using the revealed preference (RP) survey method to design the questionnaire would cause some limitations and make the method unsuitable for the study. Compared with RP surveys, SP surveys are more conducive to collecting data on scenarios that cannot be directly observed. Furthermore, the SP method can bring more flexibility and possibility, and the data obtained are more conducive to the survey participants' perception and satisfaction. Therefore, for the survey of car-sharing systems in China, the SP method is considered the best choice, and we designed a questionnaire using this method.

3.3. Modeling Method Description. The analysis and modeling of travelers' choice behavior is one of the most important research directions in traffic research [2]. The main model used in this research field is the discrete choice model. Discrete choice models can be divided into two major types of models: those with closed-form expressions and those that approximate a numerical solution based on a formula with integral values using simulation.

Discrete choice models are an effective method for analyzing the choice of the traffic mode and are used by 
many scholars. For example, Ran [8] used Nanjing residents' travel data to establish a mixed logit model to determine sixteen variables in four ways to fully explain and quantitatively apply the characteristics of the residents' travel mode selection. The mixed logit model can effectively reflect the heterogeneity of individuals and explain the behavior of residents' choice of the travel mode. However, due to the high computational cost of the simulation process for the mixed logit model, its initial use is only in a very limited estimation and application. However, in recent years, the remarkable improvement in computer performance has increased people's interest in simulation models, and the mixed logit model has gradually become one of the most widely used models in transportation research [24].

Based on the above discussion, we chose the logit model to analyze the travel behavior of car-sharing users. According to the theory of utility maximization, it is assumed that the total utility of traveler $\boldsymbol{n}$ to choose travel scheme $\boldsymbol{i}$ is $U_{\mathrm{jn}}$. Assume that the utility is a random variable:

$$
U_{\text {in }}=V_{\text {in }}+\varepsilon_{\text {in }},
$$

where $V_{\text {in }}$ is the determination or observable part of the utility of traveler $\boldsymbol{n}$ choosing scheme $\boldsymbol{I}$, and $\varepsilon_{\text {in }}$ is the uncertainty or unobserved utility portion of the utility function of the traveler $\boldsymbol{n}$ choosing scheme $\boldsymbol{i}$.

According to the utility maximization theory, the probability that traveler $\boldsymbol{n}$ chooses the scheme $\boldsymbol{i}$ is

$$
P_{\text {in }}=\operatorname{Prob}\left(U_{\text {in }}>U_{\text {jn }} ; \quad i \neq j, j \in A_{n}\right),
$$

where $0 \leq P_{\text {in }} \leq 1$. Assume that $\varepsilon$ obeys a double exponential distribution, and the expression for the general logit model probability is

$$
P_{\text {in }}=\frac{e V_{\text {in }}}{\sum_{j \in A_{n}} e V_{\text {jn }}} .
$$

When the fixed unknown parameters are replaced by random numbers subject to a distribution, the probability that scheme $\boldsymbol{i}$ is chosen should be the expected value of the probability of $\beta$ traversing all possible values, and the probability function of the mixed logit model can be regarded as the integral of the binomial logit probability function on the probability density function of $\beta$. The selection probability can be expressed as

$$
P_{\text {in }}=\int L_{\text {in }}(\beta) f\left(\frac{\beta}{\theta}\right) d \beta .
$$

In this formula is the probability of selection of the unknown parameter $\boldsymbol{\beta}$ as deduced by the above logit:

$$
L_{\text {in }}=\frac{\mathrm{eV}_{\mathrm{in}}}{\sum_{j \in A_{n}} \mathrm{eV}_{\mathrm{jn}}},
$$

where $V_{\text {in }}(\beta)=\beta^{\prime} X_{\text {in }}$. It can be seen that the standard expression of the probability of the mixed logit model is

$$
P_{\text {in }}=\int \frac{\mathrm{eV}_{\mathrm{in}}}{\sum_{j \in A_{n}} \mathrm{eV}_{\mathrm{jn}}} f\left(\frac{\beta}{\theta}\right) d \beta .
$$

The unknown parameter $\boldsymbol{\beta}$ obeys a certain probability distribution, such as normal, uniform, or lognormal, and $\boldsymbol{\theta}$ is the parameter of the probability distribution, such as the upper and lower limits of a uniform distribution. The unknown parameter $\beta$ of the mixed logit model obeys a certain distribution form, which reflects the randomness characteristics of different travelers' choices of the travel mode and overcomes the irrelevance of the ratio caused by the independence of irrelevant alternatives (IIA) of the general logit model.

Because the symbol function of Matlab software cannot find the analytical solution, we consider the approximate solution of Monte Carlo simulation [25]. The following is an approximate algorithm using a Monte Carlo simulation method [24, 26].

Step 1: seeking simulation probability $\breve{P}_{\text {in }}$

(1) First determine the initial value of $\theta$ and then randomly extract a vector $\beta$ from the probability density function $f(\beta / \theta)$, denoted as $\beta_{t}$. Remember the first time as $t=1$.

(2) Calculate the value of $L_{\text {in }}\left(\beta_{t}\right)$ according to equation (5)

(3) Repeat steps (1) and (2) $T$ times, using $T=500$ in this study. Calculate the value of $L_{\text {in }}\left(\beta_{t}\right)$ each time and record it. Then, take the average value as the simulation value of the selection probability:

$$
\breve{P}_{\text {in }}=\frac{1}{R} \sum_{r=1}^{R} L_{\text {in }}\left(\beta_{r}\right) \text {. }
$$

Previous studies have shown that increasing the number of sampling times $T$ can effectively reduce the deviation and variance of the simulation process [27, 28].

Step 2: construct a logarithmic maximum likelihood function

Remember that the total number of samples is $N$ and the number of selected limbs is J. Define the auxiliary variables

$$
y_{\text {in }}=\left\{\begin{array}{l}
1, \text { traveler } n \text { has chosen scheme } i, \\
0, \text { others. }
\end{array}\right.
$$

So, the logarithmic maximum simulation likelihood function is

$$
\operatorname{SLL}(\beta)=\sum_{n=1}^{N} \sum_{i=1}^{J} y_{i n} \ln \breve{P}_{\text {in }}
$$

Step 3: change $\theta$ to solve the likelihood function Change the value of $\theta$ until the maximum simulated likelihood function achieves the maximum value to obtain the parameter estimation value. The function solution can use the Newton-Rapson method and the gradient method.

In the above method, we apply the maximum likelihood estimation method, which expresses the 
probability of the respondents' choice behavior as a function of the unknown parameter and which can obtain the parameter estimate that maximizes the logarithmic maximum likelihood function value. This set of parameters is an estimate that best explains the sample data.

This study uses Matlab software programming to establish a model to construct the log-likelihood function of the above method. To realize the maximum likelihood of the log-likelihood function, the routine fminunc in Matlab is used to implement the unconstrained optimization descent algorithm proposed by Kalouptsidis and Psaraki [26]. Then, the parameter estimates of the characteristic variables are derived, and the factors that affect the travel behavior of car sharing are analyzed based on the simulation results.

3.4. Parameter Test. After modeling the data and performing maximum likelihood estimation to obtain the estimated values of the parameters, we must test the fitting effect of the model and study how well the estimated values of the parameters match the observed values. If the match is good, we can consider the model's fitting effect to be good (i.e., the model can effectively reflect the influencing factors of the travelers' selection behavior). The indicators for model parameter testing are

(1) McFaddenor goodness ratio is with a value between 0 and 1 ; the closer the value is to 1 , the better the fitting effect. The formula for calculating this value is

$$
\rho^{2}=1-\frac{\operatorname{SLL}(\widehat{\beta})}{\operatorname{SLL}(0)}
$$

where $\hat{\beta}$ is the parameter estimate value. Generally, in practical situations, when the value of $\rho^{2}$ reaches $0.2-0.4$, the fitting accuracy of the model can be considered to be quite high [19].

(2) $\rho^{2}=((N-K) / N) \rho^{2}$ is also an indicator of model fitting accuracy and is equivalent to the degree of freedom correction correlation coefficient in regression analysis

(3) Hit ratio

This is a test indicator that shows whether the actual selection result of a traveler matches the selection result predicted by the model. The intermediate rate calculation steps are as follows.

(1) Step 1: substitute the parameter estimation vector $\widehat{\beta}$ and the characteristic variable data $X_{\text {ink }}$ into equation (5) to find the selection probability $\widehat{P}_{\text {in }}$ of traveler $n$.

(2) Step 2: for all $n$, assume that the selection scheme with the selection probability greater than $50 \%$ is the selected scheme, and find the selection result:

$$
\widehat{y}_{\text {in }}=\left\{\begin{array}{l}
1, \widehat{P}_{\text {in }} \geq 50 \%, \\
0, \widehat{P}_{\text {in }}<50 \% .
\end{array}\right.
$$

(3) Step 3: assume that $S$ is 1 when the actual selection result $y_{i n}$ is equal to the prediction result $\hat{y}_{i n}$, and 0 otherwise. Hit ratio can be deduced from Hit $R=(1 / N) \sum^{n=1 N} S_{i n}, \quad$ where $\quad S_{i n}=\left\{\begin{array}{l}1, y_{i n}=\hat{y}_{i n} \\ 0, y_{\text {in }} \neq \hat{y}_{\text {in }}\end{array}\right.$. Generally, hit ratio is unlikely to reach $100 \%$, and if it is greater than $80 \%$, then the model's fitting accuracy is quite high.

\section{Questionnaire Design and Summary}

4.1. Questionnaire Design. Considering that car-sharing services were only recently introduced to Nanjing and the actual coverage is not widespread, the SP method is the most suitable questionnaire design method for this study. In this study, we divide the SP-based questionnaire into three parts.

In the first part of the questionnaire, we asked the demographic attributes of respondents (age, housing status, and income level). The subject of the study was the person with a driver's license. Age was divided into four groups. We defined "young people" as 18-30 years old. The typical characteristics are that they are still single, most of them are students, and their working conditions are not stable. Middle-aged people are those between the ages of 31 and 50 . They are typically married, own cars, and have stable income. The middle and old age people are defined between the ages of 51 and 60 . They have some savings and more free time. Older persons are those over the age of 60 . They have a large amount of free time and prefer to use public transport or other means of transportation when their driving ability declines due to age restrictions.

The income level of respondents is divided into four options, based on data on the average monthly income of Nanjing from Nanjing Human Resource Bureau. The four groups are listed in Table 1. In general, the high-income group is highly educated and has private cars.

The relationship between housing and family situation with likelihood of using cars and car-sharing service is considered in this study. This section also discusses issues related to traffic habits, such as car ownership, travel preferences, parking, and the use of mobile apps. Respondents were also asked to describe their preferred mode of transportation, which helps researchers to propose suggestions for mobility. Family car ownership was used to analyze the impact of car ownership on car-sharing acceptance. Questions were also included regarding the frequency of use of taxi apps to assess the relationship between the frequency of use of these apps and the likelihood of participating in car-sharing systems.

Respondents were asked whether they wished to buy a car. We assumed that people who do not own a car or who do not wish to buy a car are more likely to participate in car sharing. To assess driving experience, respondents were asked when they obtained their driving license; we assume that the longer the time since receiving a license, the richer the driving experience of respondents.

The second part of the questionnaire produced a picture of the car-sharing system. Based on an understanding of the 
TABLE 1: Monthly income category in Nanjing.

\begin{tabular}{lc}
\hline Category & Income (RMB) \\
\hline Low & $<5000$ \\
Middle & $5000-10000$ \\
Middle-high & $10000-15000$ \\
High & $>15000$ \\
\hline
\end{tabular}

SP survey methodology, we used software to design a picture of a shared car profile that provided respondents with general concepts of car-sharing services, including visual and textual forms. The image briefly introduces the main processes of using shared cars, the characteristics of shared car services, and the charging standards of several car-sharing operators in Nanjing; the aim was to increase the level of understanding of car sharing by respondents and attract more environmental protection. At the same time, it helped respondents to better understand the concept of the shared car program they choose before completing the questionnaire. This helps respondents to make better choices and improves the validity of the questionnaire. This improves the credibility of the data and reduces the error, so that the results of the simulation analysis are more reliable.

The third part of the questionnaire addresses the properties of shared cars and asks respondents whether they choose to participate in car sharing. Each interviewee was presented with three of the nine plans from Nanjing's shared-car companies, each showing multiple shared-car properties, including

(1) "Deposit fee," paid by each user before using the shared car

(2) "Fee/minute," based on the time of use

(3) "Fee/kilometer," based on the distance traveled

(4) "Distribution distance," the distance from the interviewee to where the shared car is parked

This section aims to determine the impact of these different properties on choice behavior. Our research is based on the billing methods of Nanjing's car-sharing operators; companies such as GoFun and EvCard provide point-to-point car-sharing services. Each questionnaire included three options for sharing cars: respondents were asked to choose between the three schemes; therefore, each had only the two options of "yes" or "no." This can reflect the likelihood of respondents choosing to join each shared-car system (Figure 1). Table 2 lists the shared-car schemes used for the survey.

4.2. Summary. Based on the SP-based questionnaire, this study investigates Nanjing residents' car-sharing choices. The main factors affecting shared-car travel behavior are demographic, socioeconomic, and sharing program attributes. Based on these three aspects, we set relevant questions to conduct our survey.

The questionnaire used an online survey method. The investigation period was from April 2 to April 25, 2018. A total of 189 questionnaires were completed. Based on the needs for constructing quantitative models and on the principle of complete and effective data, the quality of the questionnaire data was controlled; a number of invalid questionnaires were removed, and the questionnaire variables were discretized. There were 160 valid questionnaires, and the effective rate was $84.7 \%$.

Age and education are important characteristics of an individual's basic attributes and have certain influences on the willingness of a traveler to share a car. Women comprised $46.25 \%$ of respondents and men $53.75 \%$, which matches the gender ratio of Nanjing residents. Young people comprised $65.00 \%$ of respondents, followed by middle-aged respondents (18.75\%).

In terms of the educational level, $55.00 \%$ of respondents were undergraduates, followed by graduate students $(18.13 \%)$. In terms of family status, $28.13 \%$ of respondents were single, $16.25 \%$ was unmarried but had male (female) friends, and $55.30 \%$ was married. Most respondents $(66.87 \%)$ lived in college dormitories or rental housing. $41.25 \%$ of respondents had a low income (monthly average of $<5,000$ yuan), and $27.50 \%$ had a middle-high income $(10,000-15,000$ yuan).

$66.25 \%$ of respondents owned at least one car. Of these, $83.12 \%$ had a driver's license, and $26.26 \%$ had more than 5 years' driving experience. $68.75 \%$ of respondents said they did not wish to buy a car.

In terms of use of transportation modes, $36.25 \%$ of respondents chose public transport such as buses and subways, $26.25 \%$ chose private cars, and $18.75 \%$ preferred taxis. The remaining $18.75 \%$ of respondents chose to use a battery car or bicycle to travel. When asked about their familiarity with car sharing, the respondents were asked to rate their level of knowledge on a scale from "not familiar" to "very familiar." $63.13 \%$ of respondents said they had an understanding of the car-sharing system, $22.5 \%$ was very familiar with the concept, and $14.38 \%$ said they were not familiar with it. $91.25 \%$ of respondents indicated that they had to use software such as DiDi, and most indicated that they often use mobile applications.

When asked about the reason for using taxi software, $60.00 \%$ of respondents chose it for convenience, $54.38 \%$ chose it to save time, and $53.13 \%$ chose it because it had a cheaper price. Sharing cars, network taxis, and taxis had many similarities; therefore, the degree of convenience and the parking situation have a great influence on the choice of car sharing. Among the problems contributing to the choice of car sharing, $80.63 \%$ of respondents regarded the parking situation as an important factor. This shows that people are becoming less inclined to spend time looking for parking spaces as the pace of life gradually accelerates. $67.50 \%$ of respondents said that they use shared cars more for daily use and commuting.

Figure 2 shows that $72.09 \%$ of men chose to use a shared car program, compared to $64.86 \%$ of women, indicating that men are more willing to participate in car sharing. Young people were more likely to use car sharing (Figure 2). Some studies point out that young Chinese people's emotional identification with cars is weakening and that they now think of them simply as a mode of transport; consequently, they are more likely to accept the sharing model [29]. 
14.Car sharing scheme 1 in Nanjing , are you willing to use? *

\section{Deposit: 699 yuan}

Car models: New energy electric vehicle

Cost: 0.1 yuan $/$ minute +1.00 yuan $/ \mathrm{km}, 400$ yuan daily cap Pickup distance: $1.2 \mathrm{~km}$

Yes

No

FIGURE 1: Questionnaire of car-sharing plan one.

TABLE 2: Car-sharing scheme.

\begin{tabular}{ccccc}
\hline Plan & \multicolumn{4}{c}{ Car-sharing scheme variables } \\
& $\begin{array}{c}\text { Deposit } \\
\text { fee (yuan) }\end{array}$ & $\begin{array}{c}\text { Fee/ } \\
\text { minute (yuan) }\end{array}$ & $\begin{array}{c}\text { Fee/ } \\
\text { kilometer (yuan) }\end{array}$ & $\begin{array}{c}\text { Distribution } \\
\text { distance }(\mathrm{km})\end{array}$ \\
\hline 1 & 699 & 0.1 & 1.0 & 1.2 \\
2 & 699 & 0.2 & 1.2 & 0.5 \\
3 & 1000 & 1.2 & 0 & 1.5 \\
4 & 699 & 0.2 & 1.0 & 1.5 \\
5 & 699 & 0.4 & 1.2 & 1.0 \\
6 & 1000 & 1.4 & 0 & 0.5 \\
7 & 699 & 0.3 & 0.5 & 1.0 \\
8 & 699 & 0.6 & 1.2 & 0.5 \\
9 & 1000 & 1.0 & 0 & 1.2 \\
\hline
\end{tabular}

Figure 3 shows that people with higher education are more likely to share vehicles and have a certain interest in car sharing. In addition, respondents who have fewer cars are more willing to use car-sharing service, which is consistent with the observed situation; people who do not have cars at home will want access to more convenient car travel.

Figure 4 shows that, in both the married group and the "unmarried but not single" group, approximately $73 \%$ of respondents would prefer to share cars. This is because they have more travel needs than single people. Approximately $79 \%$ of respondents who were renting chose to use shared cars. Generally, people who have no fixed property have relatively low incomes, so they have a greater desire to share cars.

Figure 5 shows that people who are more familiar with car sharing are more likely to choose to share cars, which is consistent with past research results and indicates that shared-car promotion is necessary to promote its development. In addition, there is greater interest in car sharing among people who use a taxi app more often; this suggests that a car-sharing system with mobile apps is more likely to attract potential customers.

When asked the reasons for using shared cars, $60 \%$ of respondents stated that convenience was a reason, and $41.25 \%$ of respondents chose them to protect the environment (Figure 6). Price is also an important factor $(53.13 \%$ of respondents) and always plays a negative role in people's choice. $54.38 \%$ of respondents chose car sharing to save time, which indicates that this is also a key factor for people accepting car sharing in fast-paced cities.

When asked about the impact of parking conditions on the choice of shared vehicles, $58.13 \%$ of respondents considered it to be the determining factor, and $22.5 \%$ of respondents thought that it had a big impact (Figure 7). This indicates that, with the high number of cars and the general shortage of parking spaces in the city, shared car operators can attract potential users by adding infrastructure such as shared car pick-up and drop-off networks.

\section{Model Evaluation and Discussion}

5.1. Model Evaluation. As discussed in the previous section, demographic attributes and socioeconomic characteristics had a significant impact on individuals' choice behavior. In terms of demographics, men are expected to have a higher interest in car sharing than women, and young people, highly educated people, and low- and middle-income people may be more willing to participate in car sharing. In addition, we believe that the respondents' choices will be influenced by other factors, such as familiarity with car sharing and usage of mobile phone applications. In this section, we use Matlab software to create a mixed logit model and examine the effect of each characteristic variable on individual selection behavior. The model's characteristic variables and their meanings are provided in Table 3.

The maximum log likelihood method is used to estimate the model, analyzing the variables in Table 3, and the Matlab software is used to solve the model. The model parameter estimation results are shown in Table 4.

We set each characteristic variable in the mixed logit model to obey the normal distribution and changed the expectation and variance of the normal distribution corresponding to each variable until the maximum simulation likelihood function achieved the maximum value. This value evaluates the parameter of the characteristic variable. The simulation results of the two models are in Figures 8 and 9; the model explained well users' travel selection behavior. The McFadden value of the model is 0.2283 , the corrected McFadden value is 0.2100 , and the medium rate Hit $R=73.12 \%$, which show a good fit.

The simulation results show that the fitted precision of the mixed logit model is high, which better explains the influence mechanism of shared-car travel behavior. According to the model parameter estimation results, the expression for selecting the shared car's power function can be obtained as

$$
\begin{aligned}
V_{\text {in }}= & 0.4379 \mathrm{Gen}+0.3335 \mathrm{FS}-0.8066 \mathrm{CarO} \\
& +0.5164 \mathrm{Income}-0.8954 \mathrm{HS}-0.2119 \mathrm{Dl} \\
& +0.5483 \mathrm{Tp}+0.6030 \mathrm{Carb}+0.2947 \mathrm{CsF} \\
& +0.7789 \mathrm{UseP}-0.1960 \mathrm{Fee} / \mathrm{h}-0.0326 \mathrm{Fee} / \mathrm{km} \\
& -0.0326 \mathrm{CT} .
\end{aligned}
$$

\section{Discussion}

As expected, demographic characteristics have a significant impact on car-sharing acceptance. The simulation results show that the "Gender" parameter is estimated to be positive and shows positive significance, indicating that men are more interested in driving than women. This result is 


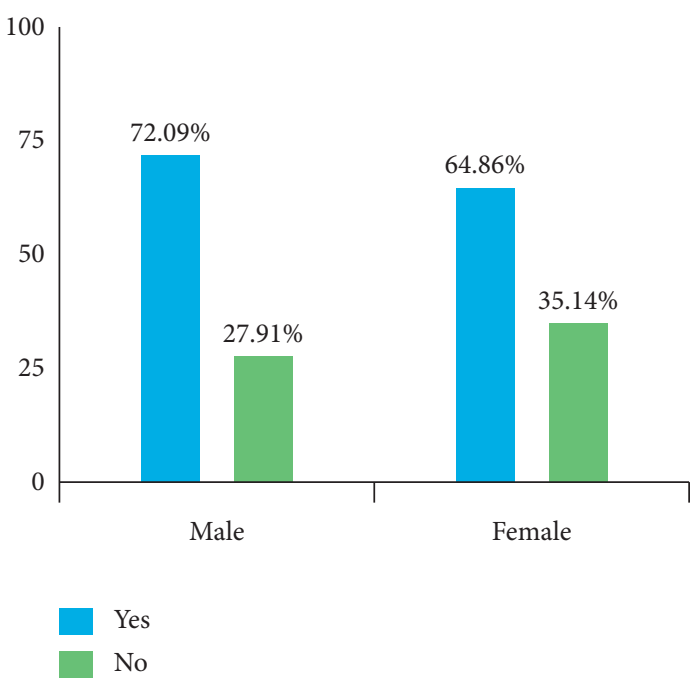

(a)

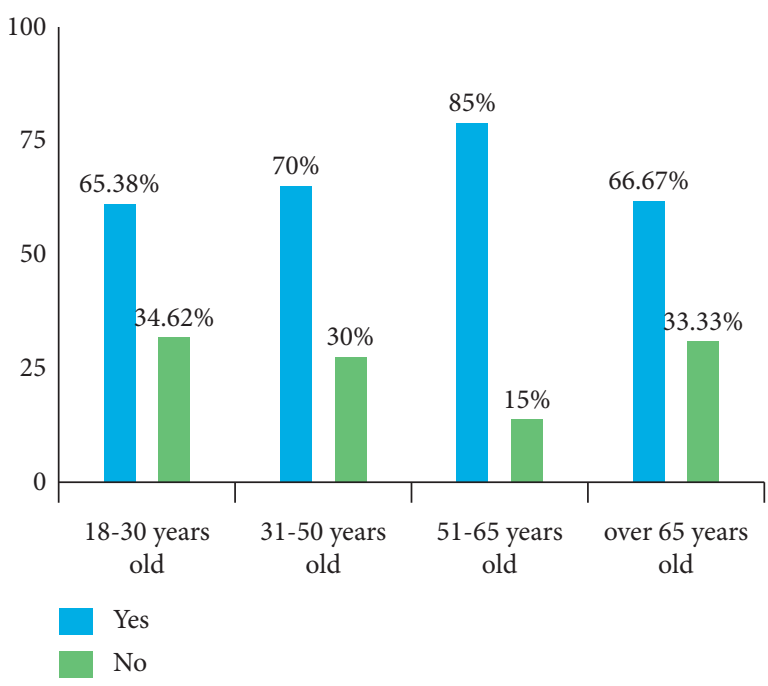

(b)

Figure 2: Breakdown of choice behavior according to sex and age.

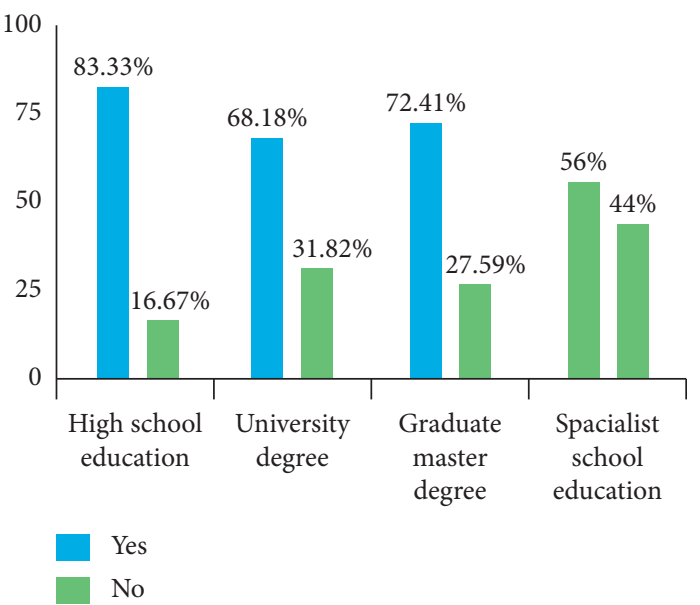

(a)

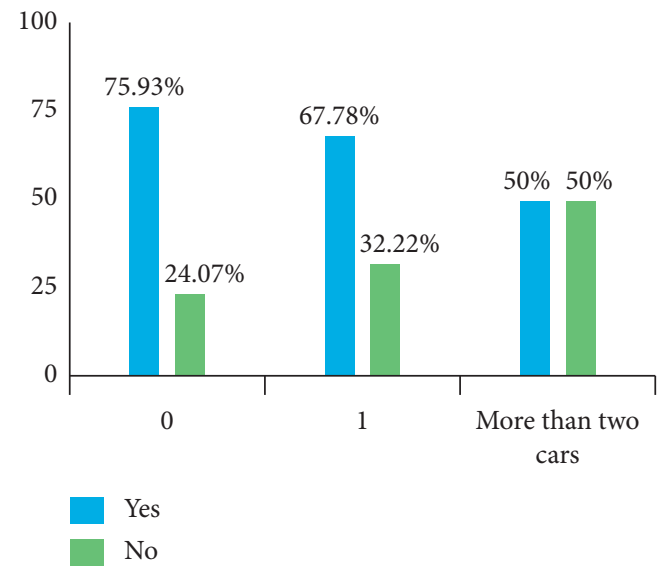

(b)

FIGURE 3: Breakdown of choice behavior according to education and private car ownership.

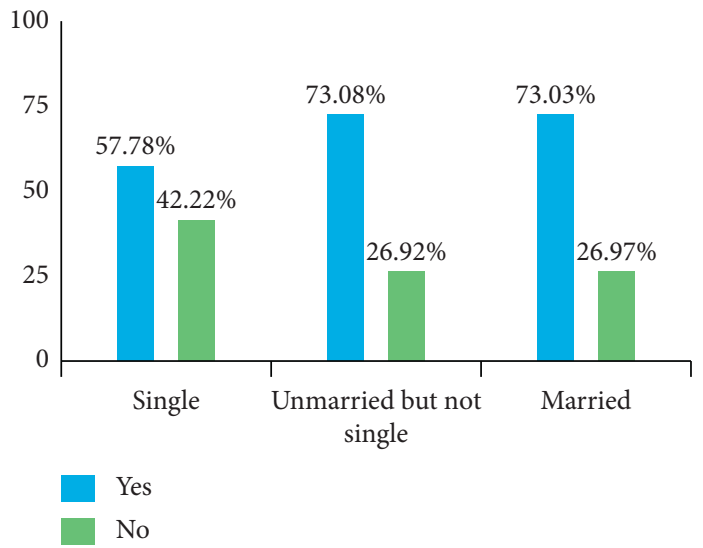

(a)

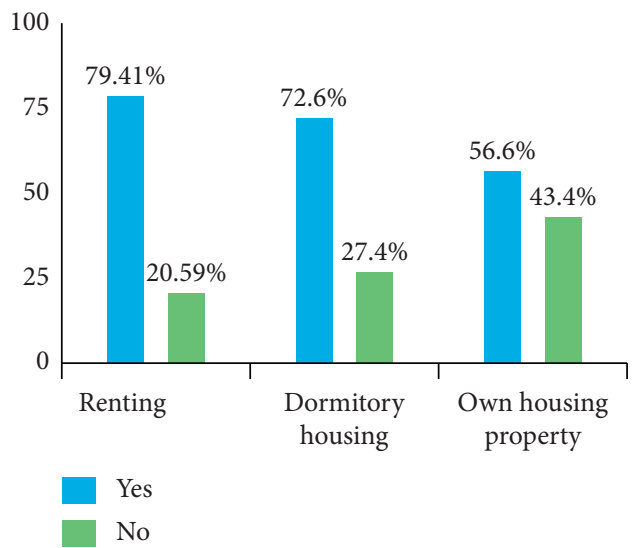

(b)

FIGURE 4: Breakdown of choice behavior according to family status and housing. 

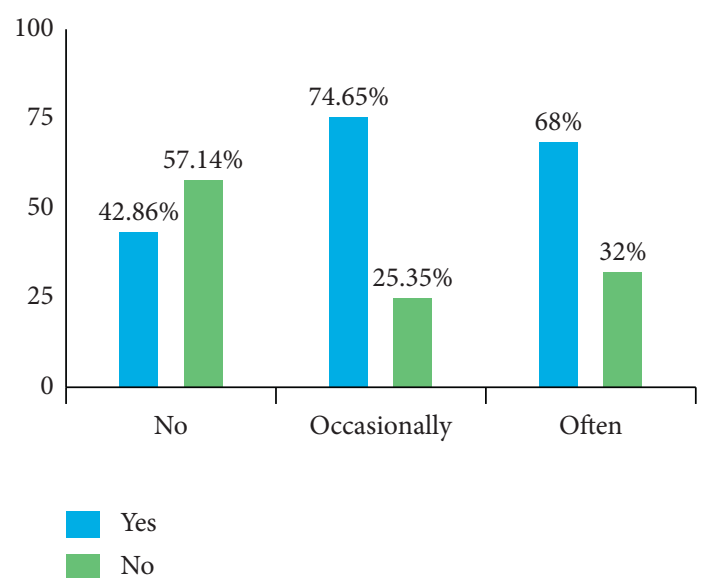

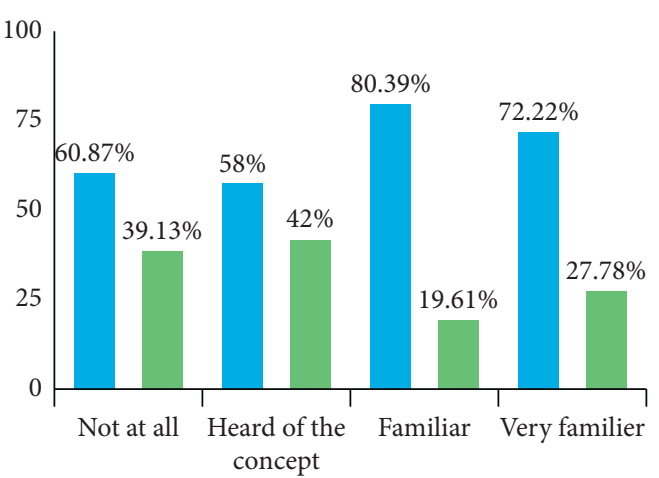

Yes

No

(a)

(b)

FIgURE 5: Breakdown of choice behavior according to taxi app usage and familiarity with car sharing.

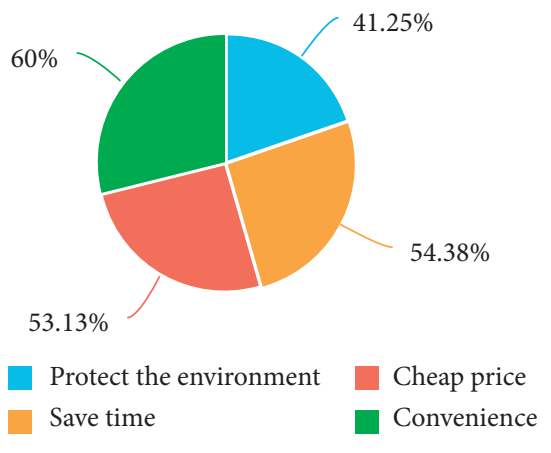

Figure 6: Reasons for using shared cars.

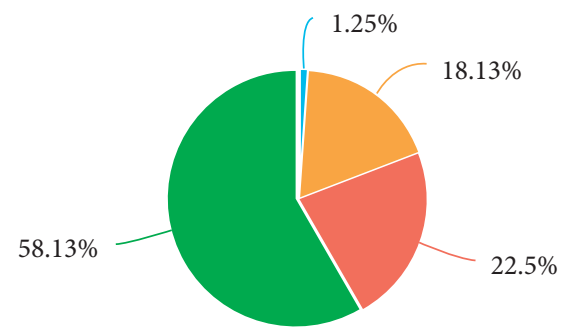

No influence

Big influence

A little influence

Determining factors

FIgURE 7: Effect of parking situation.

contrary to some studies on car sharing in North America and Europe, which found that women are more likely to join the car-sharing market. The utility of the "Age" variable is negative, indicating that younger people are more likely to choose car sharing. The "Edu" effect is positive, which means that those with higher education are more likely to use car sharing. This may be because highly educated people are more likely to be familiar with new concepts such as car sharing. Therefore, it is recommended that policy makers implement shared car systems in areas with highly educated populations, such as shopping malls and university towns.
Family status (FS) also has a positive effect, which means that married people are more likely to choose to use a shared car. The results accord with the reality that married people and those who are unmarried but not single usually have more driving needs than those who are single.

As expected, the "HS" and "CarO" variables are negative. This means that those who own a property or car are usually less interested in other transportation services such as rental cars and shared cars. The variable "Income" has a positive effect, indicating that those with higher incomes are still willing to join a car-sharing system. This is slightly different from the previous study, which may be because the age of most people in this survey were under 30 years old and thoughts of young people are changing compared with elder persons.

In terms of social and economic attributes, we provide evidence that if people are more familiar with the system, then they are more likely to join car sharing. The simulation results show that the variable "CsF" has a positive and significant effect, indicating that the likelihood of participating in car sharing increases as the respondents' familiarity with the concept increases. As expected, the variable "Mobile" has positive effects, which means that car-sharing systems that develop mobile apps are more likely to attract potential customers. The positive correlation between variables related to travel mode preferences indicates that people using private cars, especially electric car, are more interested in car sharing than those who usually travel in other ways, such as via taxis, buses, and subways. The significant positive effect of "Carb" indicates that respondents who wish to buy cars have greater interest in sharing cars, which suggests that shared cars could effectively reduce the purchase of cars in China; this is consistent with many previous studies. The variable "Dl" was estimated to be negative, indicating that as driving experience increases, people's interest in joining a carsharing system decreases.

Simulation results show that car-sharing attributes have little effect on respondents' selection behavior. The cost-related characteristic variable estimate is negative, meaning that the 
TABLE 3: Categorical variable coding table.

\begin{tabular}{|c|c|c|c|c|}
\hline Characteristic variable & Symbol & Meaning & Amount & Frequency (\%) \\
\hline \multirow{2}{*}{ Age } & \multirow{2}{*}{ Age } & 1 , male & 86 & 53.75 \\
\hline & & 0 , female & 74 & 46.25 \\
\hline \multirow{4}{*}{ Gender } & \multirow{4}{*}{ Gen } & $1,18-30$ years old & 104 & 65.00 \\
\hline & & $2,31-50$ years old & 30 & 18.75 \\
\hline & & $3,51-65$ years old & 20 & 12.50 \\
\hline & & 4 , over 65 years old & 6 & 3.75 \\
\hline \multirow{4}{*}{ Education level } & \multirow{4}{*}{ Edu } & 1 , high school education & 18 & 11.25 \\
\hline & & 2 , specialist school education & 25 & 15.63 \\
\hline & & 3 , university degree & 88 & 55.00 \\
\hline & & 4 , graduate degree & 29 & 18.13 \\
\hline \multirow{4}{*}{ Family status } & \multirow{4}{*}{ FS } & 0 , single & 45 & 28.13 \\
\hline & & 1 , unmarried but not single & 26 & 16.25 \\
\hline & & 2, married & 89 & 55.63 \\
\hline & & 0 , no car at home & 54 & 33.75 \\
\hline \multirow[t]{2}{*}{ Private car ownership } & \multirow[t]{2}{*}{ CarO } & 1 , one car at home & 90 & 56.25 \\
\hline & & 2, two cars at home & 16 & 10.00 \\
\hline \multirow{2}{*}{ Housing situation } & \multirow{2}{*}{ Hs } & 0 , renting or dormitory housing & 107 & 66.87 \\
\hline & & 1 , own house/property & 53 & 33.13 \\
\hline \multirow{4}{*}{ Income level } & \multirow{4}{*}{ Income } & 1 , monthly income below 5,000 & 66 & 41.25 \\
\hline & & 2 , income in the range $5,000-10,000$ & 26 & 16.25 \\
\hline & & 3 , income in the range $10,000-15,000$ & 44 & 27.50 \\
\hline & & 4 , income above 15,000 & 24 & 15.00 \\
\hline \multirow{5}{*}{ Driving license } & \multirow{5}{*}{$\mathrm{Dl}$} & 0, no driver's license & 27 & 16.88 \\
\hline & & 1 , driving less than 1 year & 51 & 31.88 \\
\hline & & 2 , driving $1-5$ years & 40 & 25.00 \\
\hline & & 3 , driving $5-10$ years & 21 & 13.13 \\
\hline & & 4 , driving for more than 10 years & 21 & 13.13 \\
\hline \multirow{2}{*}{ Travel preferences } & \multirow{2}{*}{$\mathrm{Tp}$} & 0 , bus or subway travel & 93 & 58.00 \\
\hline & & 1 , private car travel & 67 & 42.00 \\
\hline \multirow{2}{*}{ Car buying desire } & \multirow{2}{*}{ Carb } & 0 , do not wish to buy a car & 110 & 68.75 \\
\hline & & 1, wish to buy a car & 50 & 31.25 \\
\hline \multirow{4}{*}{ Shared car familiarity } & \multirow{4}{*}{ CsF } & 0 , not at all familiar & 23 & 14.38 \\
\hline & & 1 , heard of the concept & 50 & 31.25 \\
\hline & & 2, familiar & 51 & 31.88 \\
\hline & & 3 , very familiar & 36 & 22.50 \\
\hline \multirow{3}{*}{ Taxi software usage } & \multirow{3}{*}{ Mobile } & 0 , do not use taxi software & 14 & 8.75 \\
\hline & & 1 , occasionally use taxi software & 71 & 44.38 \\
\hline & & 2 , often use taxi software & 75 & 46.88 \\
\hline \multirow{4}{*}{ Influence of parking situation } & & 0, no effect & 2 & 1.25 \\
\hline & & 1, a little effect & 29 & 18.13 \\
\hline & Park & 2 , greater effect & 36 & 22.50 \\
\hline & & 3 , the decisive factor & 93 & 58.13 \\
\hline Using shared cars' purpose & UseP & 0 , temporary use such as moving and short trips. & 52 & 32.50 \\
\hline
\end{tabular}

TABLE 4: Mixed logit simulation results.

\begin{tabular}{lcc}
\hline Variable & Symbol & B \\
\hline Gender & Gen & 0.4379 \\
Family situation & FS & 0.3335 \\
Car ownership & CarO & -0.8066 \\
Income level & Income & 0.5164 \\
Housing situation & HS & -0.8954 \\
Driving license & $\mathrm{Dl}$ & -0.2119 \\
Travel preferences & $\mathrm{Tp}$ & 0.5483 \\
Car buying desire & $\mathrm{Carb}$ & 0.6030 \\
Shared car familiarity & $\mathrm{CsF}$ & 0.2947 \\
Purpose of usage & UseP & 0.7789 \\
Time fee & Fee/h & -0.2012 \\
Distance fee & Fee/km & -0.0335 \\
Pick up distance & $\mathrm{CT}$ & -0.0335 \\
\hline
\end{tabular}




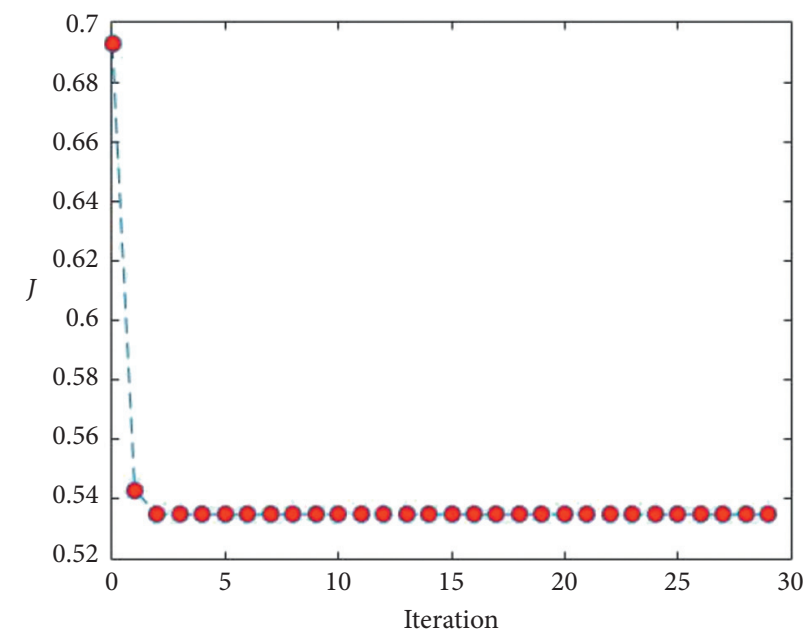

Figure 8: BL (binary logit) model likelihood function optimization.

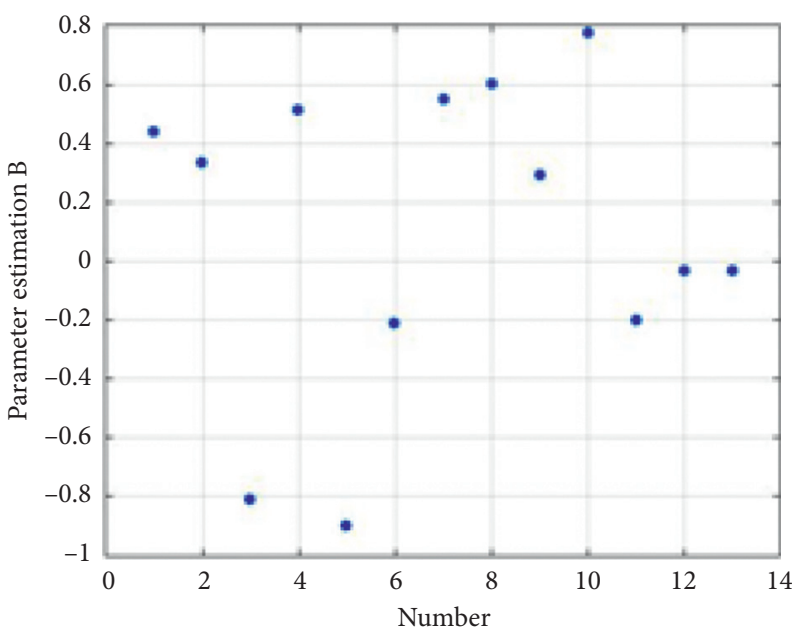

(a)

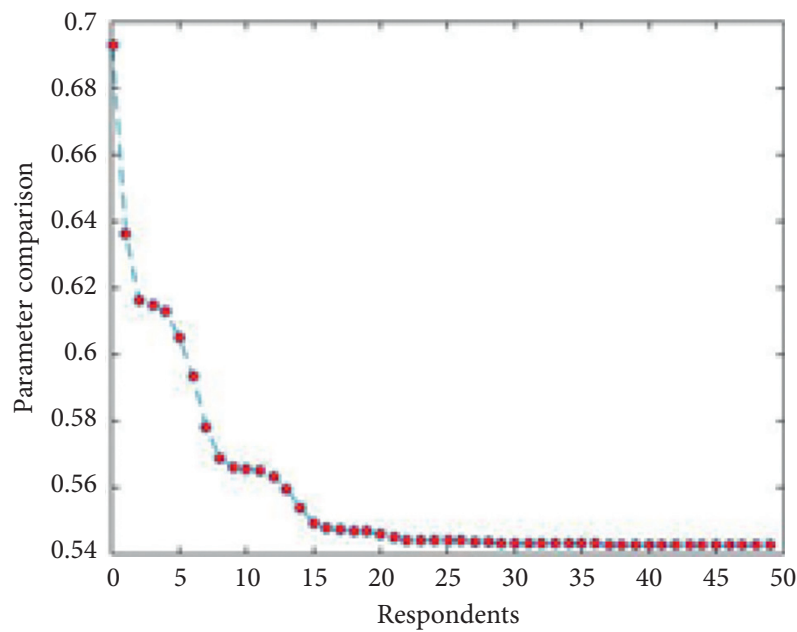

(b)

FIgURE 9: Likelihood function optimization diagram of the mixed logit model.

utility of sharing a car decreases as the cost increases. However, the estimated value of the cost per kilometer and the distance from the vehicle is small, and the impact is not significant. The following two assumptions can be used to explain the situation. First, respondents may mostly regard shared cars as shortdistance travel tools, so they are sensitive to distance costs. Note that the degree is not high; therefore, the impact of distance costs is not significant. Second, it may be that people who are willing to accept car sharing often use shared bicycles, which are increasingly popular in China; therefore, the distance to pick up cars may not be a problem.

\section{Conclusion}

This study uses the mixed logit model to investigate the factors that have an impact on the travel behavior of people using shared cars in Nanjing, China. A questionnaire was designed based on the SP method, using selected characteristic variables covering demographics, socioeconomics, and shared vehicle attributes. The basic data and estimates of model parameters analyze the influencing factors for people choosing shared car travel, identify the significant factors, and provide corresponding insights on the development of shared car schemes.

The study found that young people in Nanjing have a higher acceptance of shared cars than people in other age categories and that travel preferences, family status, private car ownership, and housing conditions have significant impacts on the selection of shared cars. Although previous studies have shown that women are more attracted to car sharing, our research shows that men are more inclined to use shared cars. More highly educated people are more willing to join a car-sharing system, indicating that people with a higher level of education are more willing to try new things. Therefore, it is suggested that the number of shared cars be increased near schools and office buildings.

Housing condition had the greatest impact on the likelihood of a traveler choosing to participate in car sharing; 
its utility coefficient is negative, indicating that people who own real estate are less likely to participate in car sharing. People who are married and people who are unmarried but single were more concerned about car sharing, which may be due to an increased demand for travel in the family and an interest in cost savings.

Familiarity with the concepts of shared cars also had a significant impact on selection results. We found that most of the respondents who were familiar with shared cars expressed their willingness to join a scheme. Therefore, it is necessary to introduce and promote car sharing to travelers, which can promote the development of car sharing in the Chinese market. The utility of "taxi software use" was also positive, indicating that the convenience of mobile Internet technology is also an important influence on the uptake of shared cars; therefore, increasing the development of mobile phone apps for shared cars can promote their popularity.

The simulation results also show that the properties of shared cars did not have a substantial impact on respondents' choices. The deposit and time costs had a more significant negative impact on the choice of respondents. Therefore, it is suggested that shared car companies consider adopting low-cost concessions to capture the market. The utility coefficient of the distance between vehicles is small, which indicates that the distance from the vehicle is not a problem for the traveler. This may be because the ready availability of shared bicycles now allows people to reach the shared car network quickly and easily. This also indicates that the cars will be used in conjunction with other public vehicles and that combining with transportation systems such as shared bicycles will attract more car-sharing customers.

In future research, we will consider more fully the influencing factors of car sharing and expand the scope of investigation and the number of samples. Because the questionnaire based on the SP method only surveyed the willingness of respondents, the choices made by respondents in the actual situation may be subjected to many other limitations or may be quite different. Therefore, it may be beneficial to combine SP and RP methods to produce survey questionnaires that provide more accurate results.

\section{Data Availability}

The data are collected and applied in Nanjing by an online questionnaire. The original data cannot be provided for privacy reasons.

\section{Conflicts of Interest}

The authors declare that there are no conflicts of interest.

\section{Acknowledgments}

This work was supported in part by the National Key Research and Development Program of China (grant 2018YFB1601101 of grant 2018YFB1601100) and in part by the National Natural Science Foundation of China (grant 71971116).

\section{References}

[1] S. Feng and Q. Li, Car Ownership Control in Chinese Mega Cities: Shanghai, Beijing and Guangzhou, Social Science Electronic Publishing, NY, USA, 2018.

[2] F. Ferrero, G. Perboli, M. Rosano, and A. Vesco, "Car-sharing services: an annotated review," Sustainable Cities \& Society, vol. 37, pp. 501-518, 2018.

[3] P. Wu, "Which battery-charging technology and insurance contract is preferred in the electric vehicle sharing business?" Transportation Research Part A: Policy and Practice, vol. 124, pp. 537-548, 2019.

[4] E. W. Martin and S. A. Shaheen, "Greenhouse gas emission impacts of car sharing in North America," IEEE Transactions on Intelligent Transportation Systems, vol. 12, no. 4, pp. 1074-1086, 2011.

[5] Y. Hui, W. Wang, M. Ding, and Y. Liu, "Behavior patterns of long-term car-sharing users in China," Transportation Research Procedia, vol. 25, pp. 4666-4682, 2017.

[6] S. A. Shaheen, A. P. Cohen, and M. S. Chung, "North American car sharing," Transportation Research Record: Journal of the Transportation Research Board, vol. 2110, no. 1, pp. 35-44, 2009.

[7] H. Nijland and J. V. Meerkerk, "Mobility and environmental impacts of car sharing in The Netherlands," Environmental Innovation \& Societal Transitions, vol. 23, pp. 84-91, 2017.

[8] X. Ran, Research on Characteristics of Residents' Travel Mode Selection Behavior in Big Cities: Taking Nanjing as an Example, Southeast University, Nanjing, China, 2016.

[9] J. Zeng, M. Scott, M. Podriguez et al., "Car sharing in a university community: assessing potential demand and distant market characteristics," Transportation Research Record: Journal of the Transportation Research Board, vol. 2110, pp. 18-26, 2009.

[10] M. Catalano, B. L. Casto, and M. Migliore, "Car sharing demand estimation and urban transport demand modelling using stated preference techniques," European Transport Trasporti Europei, vol. 40, pp. 33-50, 2008.

[11] S. D. Luca and R. D. Pace, "Modelling users' behaviour in inter-urban car sharing program: a stated preference approach," Transportation Research Part A: Policy and Practice, vol. 71, no. C, pp. 59-76, 2015.

[12] J. Zhou, "Car sharing on university campus: subsidies, commuter benefits, and their impacts on car sharing," Transportation Research Part D: Transport and Environment, vol. 32, no. 32, pp. 316-319, 2014.

[13] M. Wang, E. Martin, and S. Shaheen, "Car sharing in Shanghai, China: analysis of behavioral response to a local survey and potential competition," Transportation Research Record: Journal of the Transportation Research Board, vol. 2319, no. 1, pp. 86-95, 2012.

[14] S. Shaheen, "Innovative mobility car sharing outlook: car sharing market overview, analysis, and Trends," Spring, vol. 2, no. 1, 2013.

[15] K. Xia and M. He, "Theory and practice of foreign car sharing services," Urban Development Issues, vol. 4, pp. 87-92, 2006.

[16] H. Becker, F. Ciari, and K. W. Axhausen, "Comparing car-sharing schemes in Switzerland: user groups and usage patterns," Transportation Research Part A: Policy and Practice, vol. 97, pp. 17-29, 2017.

[17] J. Kim, S. Rasouli, and H. Timmermans, "Satisfaction and uncertainty in car-sharing decisions: an integration of hybrid choice and random regret-based models," Transportation Research Part A: Policy and Practice, vol. 95, pp. 13-33, 2017. 
[18] A. Gheorghiu and P. Delhomme, "For which types of trips do French drivers carpool? motivations underlying carpooling for different types of trips," Transportation Research Part A: Policy and Practice, vol. 113, pp. 460-475, 2018.

[19] H. Guan, Disaggregate Model-A Tool for Traffic Behavior Analysis, China Communications Press, Beijing, China, 2004.

[20] W. Zhang, Y. Qi, Y. Yan, J. Tang, and Y. Wang, "A method of emission and traveller behavior analysis under multimodal traffic condition," Transportation Research Part D: Transport and Environment, vol. 52, pp. 139-155, 2017.

[21] A. Lorimier and A. El-Geneidy, "Understanding the factors affecting vehicle usage and availability in car sharing networks: a case study of communauto car sharing system from Montréal, Canada," International Journal of Sustainable Transportation, vol. 7, no. 1, pp. 35-51, 2013.

[22] T. A. Domencich and D. L. McFadden, "Urban travel demand: a behavioral analysis," Canadian Journal of Economics/revue Canadienne D'economique, vol. 10, no. 4, 1975.

[23] P. Carroll, B. Caulfield, and A. Ahern, "Examining the potential for car-shedding in the greater Dublin area," Transportation Research Part A: Policy and Practice, vol. 106, pp. 440-452, 2017.

[24] S. Hess, K. E. Train, and J. W. Polak, "On the use of a modified Latin hypercube sampling (MLHS) method in the estimation of a mixed logit model for vehicle choice," Transportation Research Part B: Methodological, vol. 40, no. 2, pp. 147-163, 2006.

[25] G. Perboli, F. Ferrero, S. Musso, and A. Vesco, "Business models and tariff simulation in car-sharing services," Transportation Research Part A: Policy and Practice, vol. 115, pp. 32-48, 2018.

[26] N. Kalouptsidis and V. Psaraki, "Approximations of choice probabilities in mixed logit models," European Journal of Operational Research, vol. 200, no. 2, pp. 529-535, 2010.

[27] A. E. Watkins, A. Bargagliotti, and C. Franklin, "Simulation of the sampling distribution of the mean can mislead," Journal of Statistics Education, vol. 22, no. 3, p. 3, 2014.

[28] W. Zhang, F. Goerlandt, P. Kujala, and Y. Wang, "An advanced method for detecting possible near miss ship collisions from AIS data," Ocean Engineering, vol. 124, pp. 141-156, 2016.

[29] T. Yoon and R. C. Cherry, EV (Electric Vehicle) Sharing Demand Estimation: A Case Study of Beijing, China, KINTEX, Korea, 2015. 